\title{
Gichttherapie: Harnsäurespiegel unter die Sättigungsmarke senken
}

\section{Bei rezidivierenden Attacken Harnsäurewerte unter 6 mg/dl senken}

Bei Gicht sollten die Harnsäurespiegel im Serum deutlich reduziert werden, möglichst auf Werte unter $6 \mathrm{mg} / \mathrm{dl}$. Einfach erreichen lässt sich dieses Ziel mit Febuxostat, auch bei niereninsuffizienten Patienten.

Gicht, die häufigste entzündliche Arthritis in Industrieländern, wird oft nur ungenügend behandelt. Ziel der Therapie muss es laut Professorin Dr. Geraldine McCarthy, Dublin (Irland), sein, den Harnsäurespiegel im Serum unter die Sättigungsmarke zu senken. „Das ist der Eckpfeiler der Therapie." Für Patienten mit wiederkehrenden Gichtattacken, Tophi, chronischer Arthropathie sowie für Patienten, die bereits Nierensteine entwickelt haben, nannte sie einen Zielwert $\leq 6 \mathrm{mg} / \mathrm{dl}$. Die Relevanz dieses Cut-off-Wertes untermauerte sie mit den Ergebnissen einer Studie, nach der Patienten mit höheren Spiegeln sechs Attacken pro Jahr hatten. Bei niedrigeren Spiegeln trat dagegen pro Jahr nur eine Attacke auf.

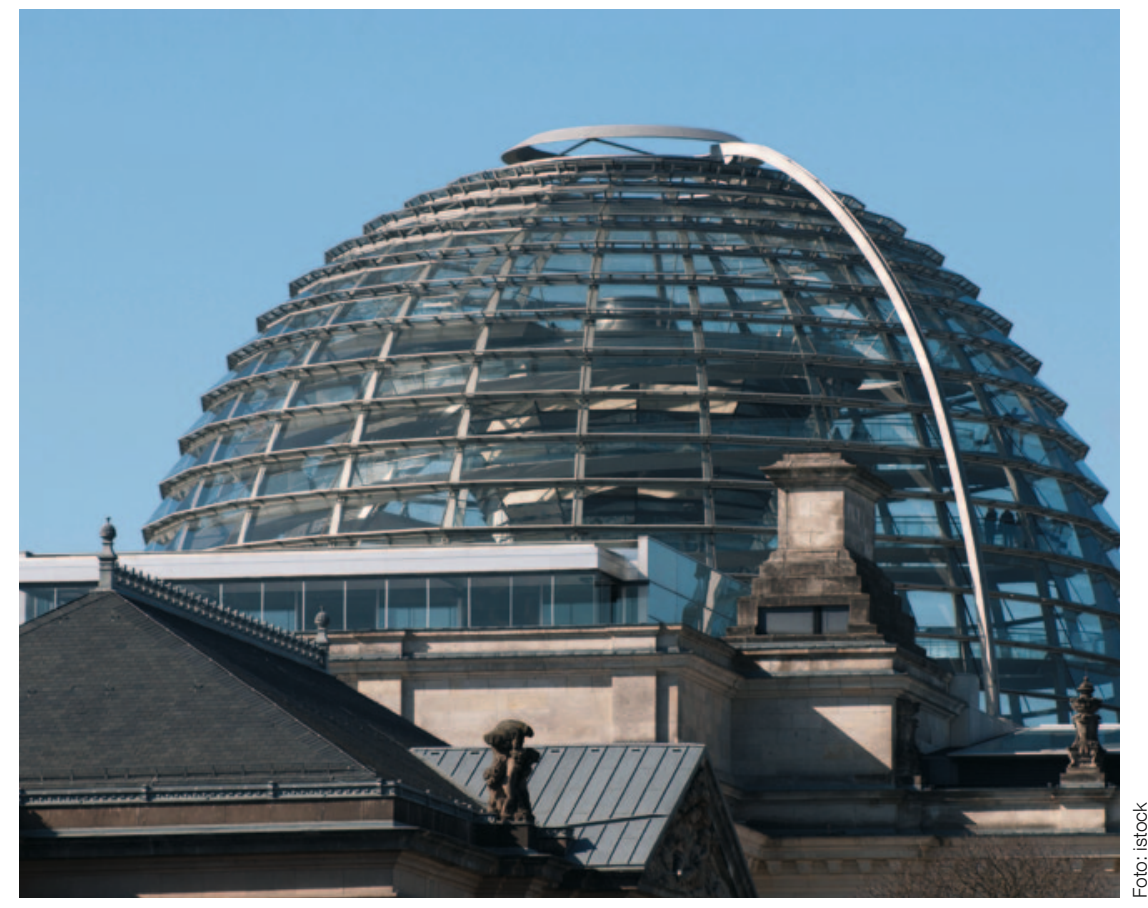

Berlin als Krongressstadt: Der Reichstag

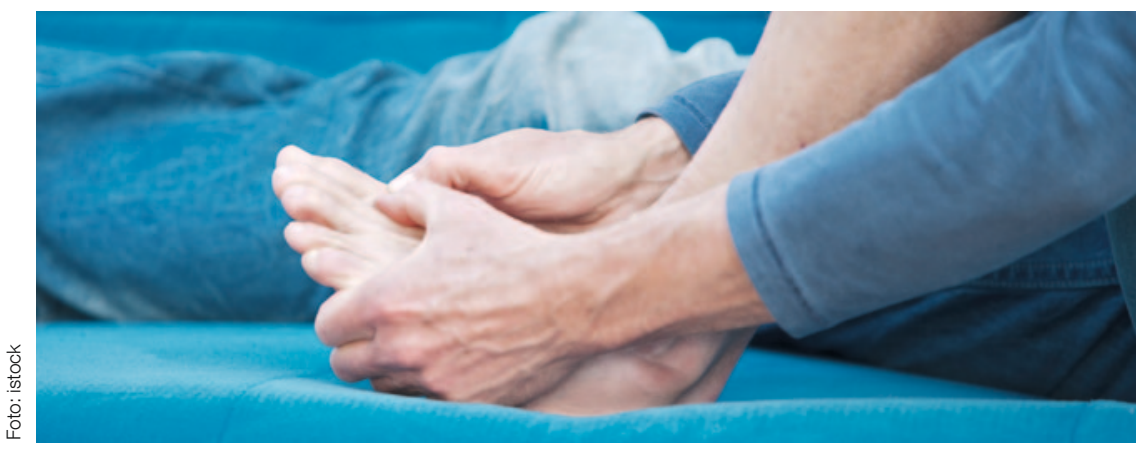

Besonders unangenehm: Immer wiederkehrende Gichtattacken
Mit Febuxostat Zielwert häufiger erreichen

Am häufigsten wird zur Senkung der Harnsäurespiegel der nicht-selektive Xanthinoxidaseinhibitor (XOI) Allopurinol eingesetzt. Bis zu 20\% der Patienten entwickeln allerdings Nebenwirkungen, $5 \%$ brechen die Therapie ab. Alternative ist der selektive XOI Febuxostat (ADENURIC ${ }^{\circ}$ ), mit dem sich auch der geforderte Zielwert häufiger erreichen lässt.

\section{EXCEL-Studie}

In der offenen Extensionsstudie EXCEL*, die Allopurinol und Febuxostat verglich, konnten Harnsäurespiegel unter $6 \mathrm{mg} / \mathrm{dl}$ mit Febuxostat deutlich häufiger erreicht werden, nämlich bei $81 \%$ der Patienten, die Febuxostat $80 \mathrm{mg} / \mathrm{d}$ erhielten und bei $87 \%$ der Patienten, die 120 mg/d erhielten (Allopurinol $300 \mathrm{mg} / \mathrm{d}: 46 \%$ ). Überlegen ist Febuxostat auch bei Patienten mit Nierenschwäche, wie eine Post-hoc-Analyse der CONFIRMS**-Studie bei älteren Patienten ( $\geq 65$ Jahre) mit leichter bis moderater renaler Insuffizienz zeigte. Mit Febuxostat $80 \mathrm{mg} / \mathrm{d}$ ließen sich bei $79 \%$ der Patienten mit moderater Nierenschwäche Harnsäurewerte unter $6 \mathrm{mg} / \mathrm{dl}$ erreichen, mit Allopurinol 200/300 mg/d gelang dies nur bei $37 \%$. Bei leichter Nierenschwäche lagen die entsprechenden Werte bei $89 \%$ und $62 \%$. Dr. Thomas Bardin, Professor für Rheumatologie an der Universität Paris, betonte zudem, dass bei Febuxostat für Gichtpatienten mit leichter bis moderater Niereninsuffizienz keine Dosisanpassung notwendig ist.

\section{Quelle:}

Satellite Symposium (Veranstalter: Menarini Pharma $\mathrm{GmbH}$ ) „Gout: the most curable joint disease is the worst treated“", Berlin 6. Juni 2012 